\title{
Investigation of rheumatoid arthritis susceptibility genes identifies association of AFF3 and CD226 variants with response to anti-tumour necrosis factor treatment
}

\author{
Rachael J L Tan, ${ }^{1}$ Laura J Gibbons, ${ }^{1}$ Catherine Potter, ${ }^{2}$ Kimme L Hyrich, ${ }^{1}$ Ann W \\ Morgan, ${ }^{3}$ Anthony G Wilson, ${ }^{4}$ John D Isaacs, ${ }^{2}$ BRAGGSS, Anne Barton ${ }^{1}$
}

- Additional data are published online only. To view these files please visit the journal online (http://ard.bmj.com)

${ }^{1}$ Arthritis Research Campaign Epidemiology Unit, University of Manchester, Manchester, UK : ${ }^{2}$ Musculoskeletal Research Group, Newcastle University, Newcastle upon Tyne, UK; ${ }^{3}$ NIHR-Leeds Musculoskeletal Biomedical Research Unit, University of Leeds, Leeds, UK; "University of Sheffield, Sheffield, UK

\section{Correspondence to Dr Anne Barton, Arthritis Research Campaign Epidemiology Unit, Stopford Building, Oxford Road, University of Manchester, Manchester M13 9PT, UK; \\ anne.barton@manchester.ac.uk \\ RJLT and LJG contributed equally to this work.}

Accepted 3 December 2009

\section{ABSTRACT}

Background Anti-tumour necrosis factor (anti-TNF) therapy has proved to be highly successful in treating rheumatoid arthritis (RA), although $30-40 \%$ of patients have little or no response. The authors hypothesise that this may be genetically determined. In other complex diseases, susceptibility genes have been shown to influence treatment response. The aim of the current study was to investigate the association of markers within confirmed RA susceptibility loci with the response to anti-TNF treatment.

Methods Eighteen single nucleotide polymorphisms (SNPs) mapping to 11 genetic loci were genotyped in 1012 patients with $\mathrm{RA}$ receiving treatment with etanercept, infliximab or adalimumab. Multivariate linear regression analyses were performed using the absolute change in 28 joint count disease activity score (DAS28) between baseline and 6-month follow-up as the outcome variable, adjusting for confounders. $p$ Values $<0.05$ were considered statistically significant and associated markers were genotyped in an additional 322 samples. Analysis was performed in the combined cohort of 1334 subjects with RA treated with anti-TNF.

Results In the combined analysis, SNPs mapping to AFF3 and CD226 had a statistically significant association with the response to anti-TNF treatment under an additive model. The $\mathrm{G}$ allele at rs10865035, mapping to AFF3, was associated with an improved response to anti-TNF treatment (coefficient -0.14 (95\% Cl -0.25 to -0.03$), p=0.015)$. At the CD226 SNP rs763361, the $\mathrm{C}$ allele conferred reduced response to treatment (coefficient 0.11 ( $95 \% \mathrm{Cl} 0.00$ to 0.22 ), $p=0.048$ ).

Conclusion These results suggest that AFF3 and CD226, two confirmed RA susceptibility genes, have an additional role in influencing the response to anti-TNF treatment.

\section{INTRODUCTION}

Rheumatoid arthritis (RA) is a chronic potentially disabling disease caused by autoimmune destruction of the synovial joints which affects approximately $1 \%$ of the Caucasian population. ${ }^{1}$ The introduction of anti-tumour necrosis factor (antiTNF) biological therapies has dramatically altered the treatment of RA as they show good efficacy in patients resistant to disease-modifying antirheumatic drugs (DMARDs) and superior efficacy in the suppression of erosive damage compared with standard DMARDs. ${ }^{2}$ However, there remains a significant non-response rate (in the region of $30-40 \%)$. The reasons for this remain largely unknown. ${ }^{3}$ Furthermore, anti-TNF therapy is associated with expensive annual treatment costs, leading to restrictions in the numbers of patients who may be prescribed these drugs. The identification of predictors of treatment response could potentially reduce the number of non-responding patients, improving the cost-effectiveness of antiTNF therapies.

Several clinical predictors of response have been determined, including the level of disability at the onset of treatment as measured by the Health Assessment Questionnaire (HAQ) (patients with higher levels of disability at the outset of therapy respond less well); concurrent therapy with DMARDs (co-administration of DMARDs improves response); and the presence of autoantibodies (presence of rheumatoid factor or anticyclic citrullinated peptide antibodies is associated with a poorer response). ${ }^{4}{ }^{5}$ However, even when these factors were combined, they accounted for less than $20 \%$ of the variance in response to anti-TNF agents in one study. ${ }^{5}$

In other complex diseases, polymorphisms in susceptibility genes have been shown to be associated with treatment response. For example, two variants in the established type 2 diabetes (T2D) susceptibility gene TCF7L2 have been shown to influence the response to treatment with sulfonylurea drugs. ${ }^{6}$ In the current study we hypothesised that polymorphisms known to have a role in susceptibility to RA may also influence the response to anti-TNF treatment.

We have previously investigated-and found no evidence for-an association of the two major RA susceptibility loci: HLA-DRB1 shared epitope alleles and the PTPN22 R620W polymorphism. ${ }^{5}$ However, with the advent of genome-wide association (GWA) studies, there has recently been enormous progress in the identification of RA susceptibility genes. There are now at least 11 additional loci for which association with RA susceptibility has been confirmed in independent data sets, and the aim of the current study was to test the association of these markers with antiTNF treatment response. 


\section{METHODS}

\section{Markers}

We selected a panel of single nucleotide polymorphism (SNP) markers mapping to 11 recently confirmed RA susceptibility loci for genotyping in a large cohort of patients treated with antiTNF agents. These included two regions around the TNFAIP3 locus on chromosome $6 \mathrm{q} 23,{ }^{7-9}$ STAT4 on chromosome $2 \mathrm{q},{ }^{7}{ }^{10-12}$ TRAF1-C5 on chromosome 9,71113 a locus encompassing the IL2 and IL21 genes on chromosome 4q27,71415 PRKCQ on chromosome 10p15,7 ${ }^{16}$ KIF5A on $12 \mathrm{q} 13,{ }^{716}$ CD 40 on 20q13, ${ }^{713}$ CCL21 on $9 \mathrm{p} 13,7$ CTLA4 on chromosome 2q, AFF3 also on chromosome $2 \mathrm{q}$ and $C D 226$ on $8 \mathrm{q} 22 .{ }^{15} 17$

\section{Samples}

The patient cohort consisted of patients with RA treated with anti-TNF drugs recruited from hospitals across the UK as part of the Biologics in Rheumatoid Arthritis Genetics and Genomics Study Syndicate (BRAGGSS). These patients were originally recruited by the British Society for Rheumatology Biologics Register (BSRBR) and subsequently invited to participate in BRAGGSS, a study of genetic predictors of anti-TNF treatment. Inclusion criteria for enrolment in BRAGGSS were: (1) physician diagnosed RA; (2) the patient must be registered with the $B S R B R$, either starting or already receiving treatment with one of the three anti-TNF drugs etanercept, infliximab or adalimumab; and (3) the patient is of Caucasian origin, thus avoiding potential spurious associations arising as a result of population stratification. Patients were excluded from the study if they had missing 28 joint count disease activity score (DAS28) data at either baseline or at follow-up (6 months) or if they had stopped treatment due to adverse events during the follow-up period. The first cohort of BRAGGSS patients used here comprised 1092 patients, while associations were investigated further in an additional 338 patients. Clinical and demographic characteristics for both cohorts are shown in table 1 .

\section{Genotyping}

Genotyping was performed with $10 \mathrm{ng}$ DNA using the Sequenom MassARRAY iPLEX system according to the manufacturer's instructions (http://www.sequenom.com/). Duplicate DNA samples were genotyped as part of quality control ( $\mathrm{QC}$ ) assessments.

\section{Analysis of data}

Statistical analyses were performed in Stata Version 9.2 (StataCorp, College Station, Texas, USA) and in PLINK (http:// pngu.mgh.harvard.edu/purcell/plink/). ${ }^{18}$ OC of DNA samples and SNPs was performed by excluding those displaying $<80 \%$ genotyping success. Multivariate linear regression analysis was used to assess the effect of each SNP genotype on response to treatment, using the continuous variable absolute change in DAS28 between baseline and 6-month follow-up as the outcome measure. Regression analyses were adjusted for confounding variables with a significant effect on anti-TNF treatment response: baseline DAS28, HAQ score, gender and concurrent DMARD therapy. Additive, genotypic, dominant and recessive models of inheritance were tested in Stata. p Values $<0.05$ were considered statistically significant and no corrections for multiple testing were performed. SNPs reaching statistical significance were genotyped in an additional cohort of patients with RA treated with anti-TNF drugs and the combined genotype data from the two cohorts were analysed. Possible differences in the effect of the associated variants on treatment response between the three anti-TNF drug types were investigated, both by drug type stratification and inclusion of an interaction term in the linear regression model.

\section{RESULTS}

A total of 18 SNPs mapping to the 11 loci investigated were selected for genotyping (table 2). These were polymorphisms with previous evidence for association with RA susceptibility including some proxy SNPs in case of assay failure, selected using SNAP. ${ }^{19}$

The initial test cohort comprised 1092 samples; 80 samples were excluded by the $<80 \%$ OC measure, leaving 1012 samples available for analysis. One SNP (rs13207033) in TNFAIP3 was excluded from analysis due to $<80 \%$ genotyping success rate, although a perfect proxy for this variant was successfully genotyped (rs13192841).

Two variants mapping to AFF3 and one to the CD226 locus demonstrated statistically significant evidence for association under an additive model (table 3) (AFF3: rs10865035, allele G coefficient -0.16 (95\% CI -0.29 to -0.03$)$, $\mathrm{p}=0.018$; rs1160542, allele G coefficient 0.15 (95\% CI 0.02 to 0.29 ), $\mathrm{p}=0.022$; CD226: rs763361, allele C coefficient 0.16 (95\% CI 0.03 to 0.29 ), $\mathrm{p}=0.016)$. $\mathrm{rs} 1160542$ served as a proxy $\left(\mathrm{r}^{2}=0.97\right)$ for $\mathrm{rs} 10865035$, so these two associations represent a single effect at AFF3.

A SNP at the STAT4 locus rs7574865 (along with the proxy SNP rs10181656) reached statistical significance under a dominant model but not in the genotypic or additive model (table 3). The association appears to be driven by the reduced response conferred by the heterozygous genotype, suggesting that this association may be a spurious finding.

In order to increase confidence in the association at these three loci, they were genotyped in an additional 338 anti-

Table 1 Characteristics for first, additional and combined cohorts (1334 samples)

\begin{tabular}{|c|c|c|c|}
\hline Characteristics & First cohort $(n=1012)$ & Additional cohort $(n=322)$ & Combined cohort $(n=1334)$ \\
\hline$M: F, n(\%)$ & $229(22.6): 783(77.4)$ & $65(20.2): 257(79.8)$ & $294(22.1): 1038$ (77.9) \\
\hline Mean (SD) age at baseline (years) & $56.5(11.1)$ & $56.7(10.5)$ & $56.6(10.95)$ \\
\hline Mean (SD) disease duration at baseline (years) & $13.9(9.8)$ & $12.7(10.2)$ & $13.6(9.89)$ \\
\hline Mean (SD) HAO score at baseline & $2.05(0.56)$ & $1.9(0.6)$ & $2.0(0.58)$ \\
\hline Current smoker/ex-smoker/never smoked, n (\%) & $171(16.9) / 422(41.7) / 409(40.4)$ & $46(14.3) / 135(41.9) / 137(42.6)$ & $217(16.3) / 557(41.8) / 544(40.8)$ \\
\hline Receiving concurrent DMARD therapy, $\mathrm{n}(\%)$ & $720(71.2)$ & $249(77.3)$ & $968(72.7)$ \\
\hline Receiving concurrent steroid therapy, n (\%) & $414(40.9)$ & $127(39.4)$ & $541(40.6)$ \\
\hline Biologic naïve, n (\%) & $949(93.8)$ & $298(92.6)$ & $1246(93.5)$ \\
\hline Mean (SD) baseline DAS28 & $6.69(0.98)$ & $6.53(0.98)$ & $6.65(0.98)$ \\
\hline Mean (SD) change in DAS28 at 6-month follow-up & $-2.47(1.55)$ & $-2.52(1.40)$ & $-2.48(1.52)$ \\
\hline
\end{tabular}

DAS28, 28-joint count disease activity score; DMARD, disease-modifying antirheumatic drug; HAQ, Health Assessment Questionnaire. 
Table 2 Details of 18 confirmed RA susceptibility gene SNPs selected for genotyping

\begin{tabular}{|c|c|c|c|c|}
\hline Gene & SNP & Chr & bp & Reason for selection \\
\hline AFF3 & rs10865035 & 2 & 100202166 & $\begin{array}{l}\text { Most associated T1D SNP } \\
\text { associated with RA } \text { RA }^{15}\end{array}$ \\
\hline AFF3 & rs 1160542 & 2 & 100198587 & rs10865035 proxy $\left(r^{2}=0.967\right)$ \\
\hline STAT4 & rs7574865 & 2 & 191672878 & $\begin{array}{l}\text { Strongest association in US and UK } \\
\text { studies }^{10-12}\end{array}$ \\
\hline STAT4 & rs101816566 & 2 & 191678124 & rs7574865 proxy $\left(r^{2}=0.951\right)$ \\
\hline CTLA4 & rs231775 & 2 & 204440959 & $\begin{array}{l}+49 \text { exon } 17 \mathrm{~A} \rightarrow \mathrm{G} \text { SNP, implicated } \\
\text { in autoimmunity }\end{array}$ \\
\hline CTLA4 & rs3087243 & 2 & 204447164 & Associated in US population ${ }^{715}$ \\
\hline $\begin{array}{l}\text { IL2/IL21 } \\
\text { locus }\end{array}$ & rs6822844 & 4 & 123728871 & $\begin{array}{l}\text { Most associated celiac disease SNP } \\
\text { associated with T1D and RA } \text { RA }^{714} 15\end{array}$ \\
\hline TNFAIP3 & rs13207033 & 6 & 138007111 & $\begin{array}{l}\text { Most strongly associated SNP in } \\
\text { US study }{ }^{9}\end{array}$ \\
\hline TNFAIP3 & rs13192841 & 6 & 138008907 & $\begin{array}{l}\text { rs } 13207033 \text { proxy }\left(r^{2}=1\right) \text {; second } \\
\text { US SNP9 }\end{array}$ \\
\hline TNFAIP3 & rs6920220 & 6 & 138048197 & $\begin{array}{l}\text { Most strongly associated SNP in } \\
\text { UK study }\end{array}$ \\
\hline TNFAIP3 & rs5029937 & 6 & 138236844 & Intron 2 SNP \\
\hline CCL21 & rs2812378 & 9 & 34700260 & $\begin{array}{l}\text { Most strongly associated SNP at } \\
\text { locus }^{7}\end{array}$ \\
\hline TRAF1 & rs 10760130 & 9 & 122741811 & Most strongly associated UK SNP11 \\
\hline TRAF1 & rs2900180 & 9 & 122746203 & Most strongly associated US SNP 13 \\
\hline PRKCO & rs 4750316 & 10 & 6433266 & Most associated SNP at locus ${ }^{16}$ \\
\hline KIF5A & rs1678542 & 12 & 56254982 & $\begin{array}{l}\text { Most strongly associated SNP at } \\
\text { locus }^{16}\end{array}$ \\
\hline CD226 & rs763361 & 18 & 65682622 & $\begin{array}{l}\text { Most associated T1D SNP, } \\
\text { associated with MS, AITD and RA }{ }^{17}\end{array}$ \\
\hline CD40 & rs4810485 & 20 & 44181354 & $\begin{array}{l}\text { Most strongly associated SNP at } \\
\text { locus }^{7}\end{array}$ \\
\hline
\end{tabular}

A1TD, autoimmune thyroid disease; bp, base pairs; Chr, chromosome; MS, multiple sclerosis; RA, rheumatoid arthritis; SNP, single nucleotide polymorphism; T1D, type 1 diabetes.

TNF-treated RA samples which were reduced to 322 samples after the $80 \%$ QC measure. The clinical characteristics of this cohort are shown in table 1 and are similar to the initial cohort, allowing the data from both cohorts to be combined for analysis. The results of analysis of the additional samples alone are given in table $\mathrm{S} 1$ in the online supplement.

Power calculations performed in QUANTO computer program (2006) showed that, under an additive or a dominant model, the sample size in the combined cohort $(n=1334)$ provided $>99 \%$ power to detect a difference in DAS28 score of $\geq 0.6$ units (a clinically important change) at minor allele frequencies of $\geq 0.05$.

The SNPs mapping to AFF3 and CD226 remained statistically significantly associated with response under an additive model (AFF3: rs10865035, allele G coefficient -0.14 (95\% CI -0.25 to $-0.03), \mathrm{p}=0.015$; CD226: rs763361, allele $\mathrm{C}$ coefficient $0.11(95 \%$ CI 0.00 to 0.22 ), $p=0.048$ ) (table 4). However, the association at the STAT4 locus continued to be driven by the heterozygous genotype in the combined data. Since this seems a biologically implausible model for association, we believe that the association at STAT4 probably represents a false positive. In a separate analysis using the European League Against Rheumatism (EULAR) response criteria as the outcome measure, only rs10865035 in AFF3 was associated, with good versus poor response (OR 1.46 (95\% CI 1.13 to 1.88), $\mathrm{p}=0.0036$ ) (see table S2 in online supplement).

It is possible that polymorphisms may have different effects on the treatment response depending on which of the three anti-TNF drugs was used. Despite apparent drugspecific effects upon stratification by drug type, interaction analysis revealed no statistically significant difference in treatment response between the three anti-TNF biological agents for either of the associated SNPs (additive model, AFF3: rs10865035, $\mathrm{p}=0.26$; CD226: rs763361, $\mathrm{p}=0.51$ ) (see table S3 in online supplement).

\section{DISCUSSION}

This investigation of RA susceptibility loci in response to anti-TNF treatment is the largest study of genetic predictors of anti-TNF response performed to date. We have detected nominally significant effects at RA susceptibility variants mapping to the AFF3 and CD226 genes.

The identification of an effect on treatment response conferred by polymorphism within a susceptibility gene is not surprising as there are several examples in the literature where complex disease susceptibility genes encode therapeutic targets. For example, in T2D, the established susceptibility gene PPARG encodes a protein which is a target for the thiazolidinedione drugs. ${ }^{20}$ In RA the drug abatacept, a CTLA4 analogue, was shown to be an effective therapy before the CTLA4 gene was unequivocally demonstrated as associated with susceptibility to RA.7 1521 There are now examples of polymorphisms within susceptibility genes that influence response to treatment, such as variation in the T2D susceptibility gene TCF7L2 which predicts response to sulfonylureas. ${ }^{6}$

However, the association of CD226 and AFF3 variants with the anti-TNF response is weak, and the addition of these markers into predictive models including clinical variables has only a modest effect, increasing the $\mathrm{R}^{2}$ value from $15.7 \%$ to $17.0 \%$. This is in contrast to the large genetic effects seen in studies such as those of response to warfarin therapy. For example, genetic variants in the two genes VKORC1 and CYP2C9 account for about $40 \%$ of the variance in warfarin dose. ${ }^{22}$ In that case the genes were originally targeted as candidates because they were known to lie on the warfarin metabolic pathway, and it may be argued that major genetic effects on the anti-TNF response might be expected to arise from variation within genes implicated in the TNF pathway. However, previous investigations by our group have failed to detect an association between a number of such genes and treatment response. ${ }^{23}$ One notable exception is the association between the TNF -308 SNP and the response to etanercept, but not infliximab. ${ }^{24}$

Even with the warfarin story, although major genetic effects have been identified, inclusion of these into models with clinical variables remains only moderately predictive of warfarin dose required or time to stabilise international normalised ratio. ${ }^{25}$ A subsequent GWA study confirmed an association with VKORC1 and CYP2C9 loci and identified numerous signals which may represent other loci with smaller effects on warfarin requirements. Incorporation of these smaller effects may be required to develop accurate models of prediction. ${ }^{26}$ Hence, the weak effects detected in the current study may yet prove to be clinically important when combined with other predictors of response to anti-TNF therapy.

In order to detect subtle effects, studies must be adequately powered. One of the most important strengths of this study is the large sample size employed; almost all similar investigations (with notable exceptions ${ }^{5} 2324$ ) have focused on $<500$ patients with RA. The current sample size provided very high power $(>99 \%)$ to detect a change in DAS28 of 0.6 units at minor allele frequency $\geq 0.05$. We are therefore confident in excluding modest effects at the variants that did not demonstrate evidence of association in our study. 


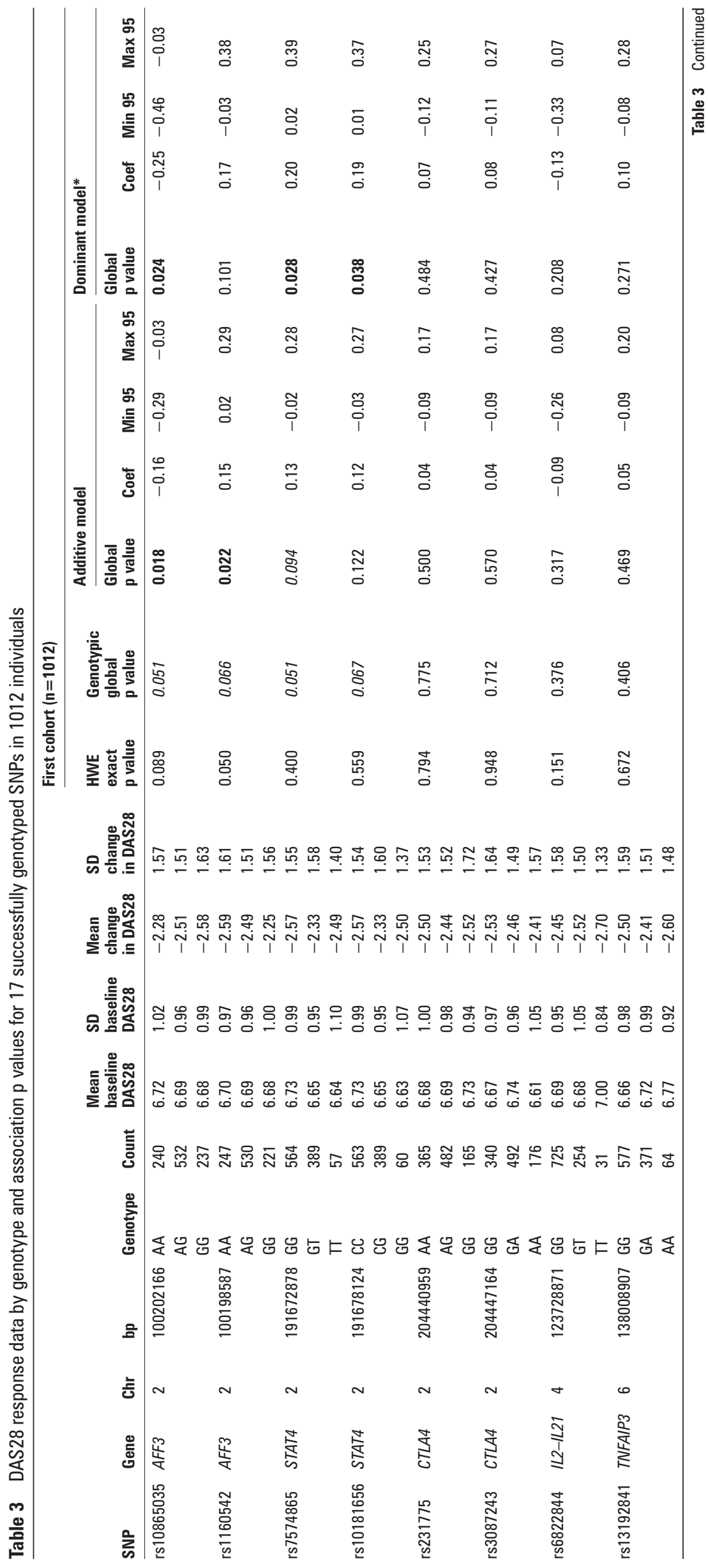




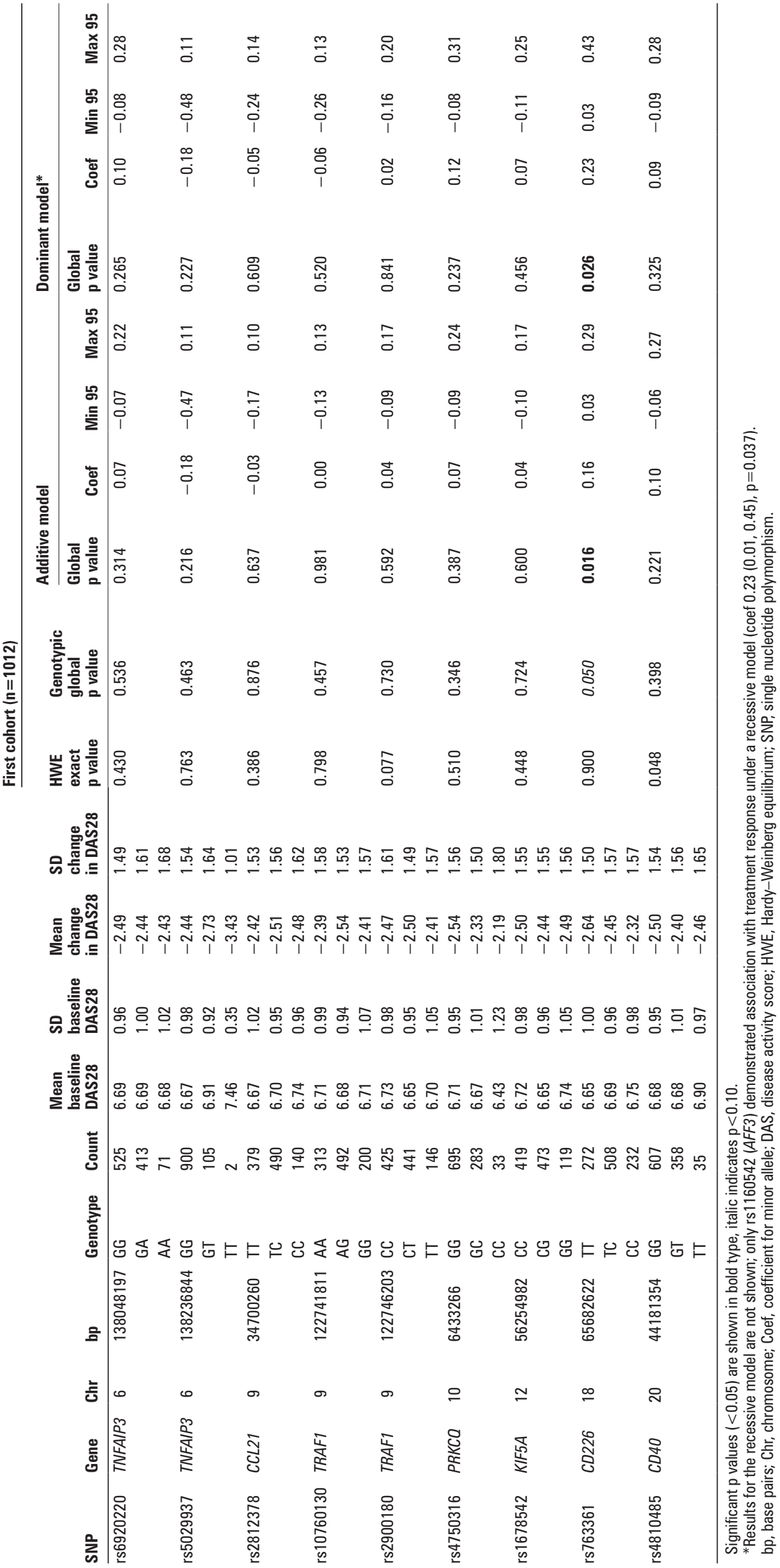




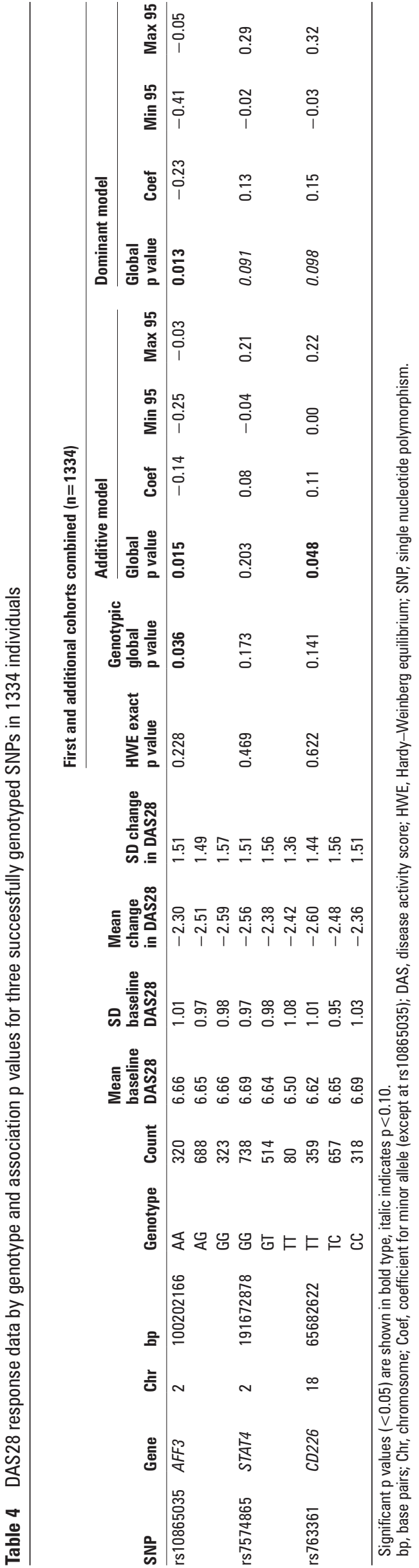

The associated rs10865035 SNP maps to the $5^{\prime}$ upstream region of AFF3 located on chromosome 2q11. Interestingly, the SNP was associated not only with change in the DAS28 but also with EULAR response criteria; indeed, for the latter analysis, the association remained statistically significant even after applying a stringent Bonferroni correction $\left(\mathrm{p}_{\mathrm{c}}=0.049\right)$. The gene, also known as $A F 4 / F M R 2$, is preferentially expressed on lymphoid cells and encodes a family of transcription factors that are thought to be implicated in the function of the lymphoid system. ${ }^{27}$ We speculate that variation in AFF3 may lead to an upregulated inflammatory response by lymphocytes, resulting in more circulating proinflammatory molecules and leading to a reduced response to TNF antagonists; further studies will be required to explore this.

The CD226 gene maps to chromosome 18q22 and encodes a type I membrane protein molecule expressed on the surface of haematopoietic cells which is involved in the triggering of both $\mathrm{T}$ and NK cell cytotoxicity. The associated variant (rs763361) is a non-synonymous SNP encoding a glycine to serine substitution and carriage of the minor allele has previously been reported to be associated with RA susceptibility. ${ }^{17}$ Alteration of $\mathrm{T}$ and NK cell cytotoxicity could once again lead to greater proinflammatory molecule production, thereby explaining why there is a reduced response to anti-TNF drugs.

A limitation of the current investigation is that no correction for multiple testing was applied and, if it was applied, the associations with change in DAS28 would not remain statistically significant $\left(A F F 3, p_{c}=0.195 ; C D 226, p_{c}=0.624\right)$. It is therefore important that the findings of this study are validated in an independent cohort, but such validation was beyond the scope of the current study. Our strategy was to maximise sample size by genotyping all available DNA samples rather than splitting the cohort into test and confirmatory data sets. It is therefore possible that the associations may have arisen due to a type I error. However, our findings are in keeping with those in other complex diseases, in that susceptibility genes may also influence treatment response. ${ }^{6}$

In summary, we provide evidence for a weak association between SNPs in the AFF3 and CD226 RA susceptibility loci and response to anti-TNF treatment in patients with RA. The percentage of the variance explained by these genetic markers is only $1.3 \%$. It is too early to say whether the response to antiTNF treatment will be conferred through a number of genes, each with a small effect size, or whether genes exist that predict a large percentage of variance to treatment. Candidate gene studies have had limited success, however, in identifying predictors. We hypothesise that the response to treatment is polygenic and that well-powered GWA studies should be able to identify a genetic signature to identify those patients most-or, indeed, leastlikely to benefit from these expensive but effective therapies.

Acknowledgements The authors thank the Arthritis Research Campaign for their support (arc grant reference no 17552). The authors are also grateful to the NIHR Manchester Biomedical Research Centre for support.

Competing interests None.

Ethics approval This study was approved by the South Manchester ethics committee (COREC 04/01403/37).

Provenance and peer review Not commissioned; externally peer reviewed. Patient consent Obtained.

\section{REFERENCES}

1. Symmons D, Turner G, Webb R, et al. The prevalence of rheumatoid arthritis in the United Kingdom: new estimates for a new century. Rheumatology (Oxford) 2002;41:793-800.

2. Lipsky PE, van der Heijde DM, St Clair EW, et al. Infliximab and methotrexate in the treatment of rheumatoid arthritis. Anti-Tumor Necrosis Factor Trial in 
Rheumatoid Arthritis with Concomitant Therapy Study Group. N Engl J Med 2000;343:1594-602.

3. Coenen MJ, Toonen EJ, Scheffer $\mathrm{H}$, et al. Pharmacogenetics of anti-TNF treatment in patients with rheumatoid arthritis. Pharmacogenomics 2007;8:761-73.

4. Hyrich KL, Watson KD, Silman AJ, et al. Predictors of response to anti-TNF-alpha therapy among patients with rheumatoid arthritis: results from the British Society for Rheumatology Biologics Register. Rheumatology (Oxford) 2006;45:1558-65.

5. Potter C, Hyrich KL, Tracey A, et al. Association of rheumatoid factor and anticyclic citrullinated peptide positivity, but not carriage of shared epitope or PTPN22 susceptibility variants, with anti-tumour necrosis factor response in rheumatoid arthritis. Ann Rheum Dis 2009;68:69-74.

6. Pearson ER, Donnelly LA, Kimber C, et al. Variation in TCF7L2 influences therapeutic response to sulfonylureas: a GoDARTs study. Diabetes 2007;56:2178-82.

7. Raychaudhuri S, Remmers EF, Lee AT, et al. Common variants at CD40 and other loci confer risk of rheumatoid arthritis. Nat Genet 2008;40:1216-23.

8. Thomson W, Barton A, Ke X, et al. Rheumatoid arthritis association at 6q23. Nat Genet 2007;39:1431-3.

9. Plenge RM, Cotsapas $C$, Davies $L$, et al. Two independent alleles at $6 q 23$ associated with risk of rheumatoid arthritis. Nat Genet 2007;39:1477-82.

10. Remmers EF, Plenge RM, Lee AT, et al. STAT4 and the risk of rheumatoid arthritis and systemic lupus erythematosus. N Engl J Med 2007;357:977-86.

11. Barton A, Thomson W, Ke X, et al. Re-evaluation of putative rheumatoid arthritis susceptibility genes in the post-genome wide association study era and hypothesis of a key pathway underlying susceptibility. Hum Mol Genet 2008;17:2274-9.

12. Lee HS, Remmers EF, Le JM, et al. Association of STAT4 with rheumatoid arthritis in the Korean population. Mol Med 2007;13:455-60.

13. Plenge RM, Seielstad M, Padyukov L, et al. TRAF1-C5 as a risk locus for rheumatoid arthritis - a genomewide study. N Engl J Med 2007;357:1199-209.

14. Zhernakova A, Alizadeh BZ, Bevova M, et al. Novel association in chromosome 4q27 region with rheumatoid arthritis and confirmation of type 1 diabetes point to a general risk locus for autoimmune diseases. Am J Hum Genet 2007;81:1284-8.

15. Barton A, Eyre S, Ke X, et al. Identification of AF4/FMR2 family, member 3 (AFF3) as a novel rheumatoid arthritis susceptibility locus and confirmation of two further panautoimmune susceptibility genes. Hum Mol Genet 2009;18:2518-22.
16. Barton A, Thomson W, Ke X, et al. Rheumatoid arthritis susceptibility loci at chromosomes 10p15, 12q13 and 22q13. Nat Genet 2008;

40:1156-9.

17. Hafler JP, Maier LM, Cooper JD, et al. CD226 Gly307Ser association with multiple autoimmune diseases. Genes Immun 2009:10:5-10.

18. Purcell S, Neale B, Todd-Brown K, et al. PLINK: a tool set for wholegenome association and population-based linkage analyses. Am J Hum Genet 2007:81:559-75.

19. Johnson AD, Handsaker RE, Pulit SL, et al. SNAP: a web-based tool for identification and annotation of proxy SNPs using HapMap. Bioinformatics 2008;24:2938-9.

20. Stumvoll M, Häring H. Insulin resistance and insulin sensitizers. Horm Res 2001;55(Suppl 2):3-13.

21. Korhonen R, Moilanen E. Abatacept, a novel CD80/86-CD28 T cell co-stimulation modulator, in the treatment of rheumatoid arthritis. Basic Clin Pharmacol Toxicol 2009;104:276-84.

22. Bodin L, Verstuyft C, Tregouet DA, et al. Cytochrome P450 2C9 (CYP2C9) and vitamin $\mathrm{K}$ epoxide reductase (VKORC1) genotypes as determinants of acenocoumarol sensitivity. Blood 2005;106:135-40.

23. Bowes JD, Potter C, Gibbons LJ, et al. Investigation of genetic variants within candidate genes of the TNFRSF1B signalling pathway on the response to anti-TNF agents in a UK cohort of rheumatoid arthritis patients. Pharmacogenet Genomics 2009:19:319-23.

24. Maxwell JR, Potter C, Hyrich KL, et al. Association of the tumour necrosis factor-308 variant with differential response to anti-TNF agents in the treatment of rheumatoid arthritis. Hum Mol Genet 2008;17:3532-8.

25. Klein TE, Altman RB, Eriksson N, et al. Estimation of the warfarin dose with clinical and pharmacogenetic data. N Engl J Med 2009;360:753-64.

26. Cooper GM, Johnson JA, Langaee TY, et al. A genome-wide scan for common genetic variants with a large influence on warfarin maintenance dose. Blood 2008:112:1022-7.

27. Ma C, Staudt LM. LAF-4 encodes a lymphoid nuclear protein with transactivation potential that is homologous to AF-4, the gene fused to MLL in $\mathrm{t}(4 ; 11)$ leukemias. Blood 1996;87:734-45. 


\section{Corrections}

The department of one of the authors who co-authored all of the below papers has found that the affiliations were not correct. The correct affiliations for Professor P Emery, for all of the below articles, are: ${ }^{1}$ Section of Musculoskeletal Disease, Leeds Institute of Molecular Medicine, University of Leeds; ${ }^{2}$ NIHR Leeds Musculoskeletal Biomedical Research Unit, Leeds Teaching Hospitals Trust, Leeds, UK.

1. Keystone E, Emery P, Peterfy CG, et al. Rituximab inhibits structural joint damage in patients with rheumatoid arthritis with an inadequate response to tumour necrosis factor inhibitor therapies. Ann Rheum Dis 2009;68:216-21.

2. Doward LC, McKenna SP, Whalley D, et al. The development of the L-OoL: a quality-of-life instrument specific to systemic lupus erythematosus. Ann Rheum Dis 2009;68:196-200.

3. Potter C, Hyrich KL, Tracey A, et al. Association of rheumatoid factor and anticyclic citrullinated peptide positivity, but not carriage of shared epitope or PTPN22 susceptibility variants, with anti-TNF response in RA. Ann Rheum Dis 2009;68:69-74.

4. Smolen JS, Han C, van der Heijde DM, et al.; Active-Controlled Study of Patients Receiving Infliximab for the Treatment of Rheumatoid Arthritis of Early Onset (ASPIRE) Study Group. Radiographic changes in rheumatoid arthritis patients attaining different disease activity states with methotrexate monotherapy and infliximab plus methotrexate: the impacts of remission and tumour necrosis factor blockade. Ann Rheum Dis 2009;68:823-7.

5. Buch MH, Boyle DL, Rosengren S, et al. Mode of action of abatacept in rheumatoid arthritis patients having failed tumour necrosis factor blockade: a histological, gene expression and dynamic magnetic resonance imaging pilot study. Ann Rheum Dis 2009;68:1220-7.

6. Emery P, Van Vollenhoven R, Ostergaard M, et al. Guidelines for initiation of antitumour necrosis factor therapy in rheumatoid arthritis: similarities and differences across Europe. Ann Rheum Dis 2009;68:456-9.

7. Bejarano V, Conaghan PG, Proudman SM, et al. Long-term efficacy and toxicity of ciclosporin A in combination with methotrexate in poor prognosis rheumatoid arthritis Ann Rheum Dis 2009;68:761-3.

8. Rudwaleit M, Landewé R, van der Heijde D, et al. The development of Assessment of SpondyloArthritis international Society classification criteria for axial spondyloarthritis (part I): classification of paper patients by expert opinion including uncertainty appraisal. Ann Rheum Dis 2009;68:770-6.

9. Bennett AN, Marzo-Ortega H, Emery P, et al.; Leeds Spondyloarthropathy Group. Diagnosing axial spondyloarthropathy. The new Assessment in SpondyloArthritis international Society criteria: MRI entering centre stage. Ann Rheum Dis 2009;68:765-7.

10. Marzo-Ortega H, McGonagle D, O'Connor P, et al. Baseline and 1-year magnetic resonance imaging of the sacroiliac joint and lumbar spine in very early inflammatory back pain. Relationship between symptoms, HLA-B27 and disease extent and persistence. Ann Rheum Dis 2009;68:1721-7.

11. Gilworth G, Emery P, Gossec L, et al. Adaptation and cross-cultural validation of the rheumatoid arthritis work instability scale (RA-WIS). Ann Rheum Dis 2009;68:1686-90.

12. Gilworth G, Emery P, Gossec L, et al. Adaptation and cross-cultural validation of the RA-WIS (Work Instability Scale). Ann Rheum Dis 2009;68:1686-90.

13. Jarrett SJ, Sivera F, Cawkwell LS, et al. MRI and clinical findings in patients with ankylosing spondylitis eligible for anti-tumour necrosis factor therapy after a short course of etoricoxib. Ann Rheum Dis 2009;68:1466-9.

14. Haugeberg G, Conaghan PG, Quinn $\mathrm{M}$, et al. Bone loss in patients with active early rheumatoid arthritis: infliximab and methotrexate compared with methotrexate treatment alone. Explorative analysis from a 12-month randomised, double-blind, placebo-controlled study. Ann Rheum Dis 2009;68:1898-901.

15. Genovese MC, Breedveld FC, Emery P, et al. Safety of biological therapies following rituximab treatment in rheumatoid arthritis patients. Ann Rheum Dis 2009;68:1894-7

16. Kekow J, Moots RJ, Emery P, et al. Patient-reported outcomes improve with etanercept plus methotrexate in active early rheumatoid arthritis and the improvement is strongly associated with remission: the COMET trial. Ann Rheum Dis 2010;69:222-5

17. Furst DE, Keystone EC, Fleischmann R, et al. Updated consensus statement on biological agents for the treatment of rheumatic diseases, 2009. Ann Rheum Dis 2010;69(Suppl 1):i2-29.

18. Freeston JE, Wakefield RJ, Conaghan PG, et al. A diagnostic algorithm for persistence of very early inflammatory arthritis: the utility of power Doppler ultrasound when added to conventional assessment tools. Ann Rheum Dis 2010;69:417-9.

19. Jones $\mathbf{E}$, Churchman SM, English A, et al. Mesenchymal stem cells in rheumatoid synovium: enumeration and functional assessment in relation to synovial inflammation level. Ann Rheum Dis 2010;69:450-7.

20. Alten RE, Zerbini C, Jeka S, et al. Efficacy and safety of pamapimod in patients with active rheumatoid arthritis receiving stable methotrexate therapy. Ann Rheum Dis 2010;69:364-7.
21. Machold KP, Landewé R, Smolen JS, et al. The Stop Arthritis Very Early (SAVE) trial, an international multicentre, randomised, double-blind, placebo-controlled trial on glucocorticoids in very early arthritis. Ann Rheum Dis 2010;69:495-502.

22. Schoels M, Knevel R, Aletaha D, et al. Evidence for treating rheumatoid arthritis to target: results of a systematic literature search. Ann Rheum Dis 2010;69:638-43.

23. Smolen JS, Aletaha D, Bijlsma JW, et al.; T2T Expert Committee. Treating rheumatoid arthritis to target: recommendations of an international task force. Ann Rheum Dis 2010;69:631-7.

24. Burr ML, Naseem H, Hinks A, et al.; BIRAC Consortium; YEAR Consortium. PADI4 genotype is not associated with rheumatoid arthritis in a large UK Caucasian population. Ann Rheum Dis 2010;69:666-70.

25. Emery $\mathbf{P}$, Durez P, Dougados $\mathrm{M}$, et al. Impact of T-cell costimulation modulation in patients with undifferentiated inflammatory arthritis or very early rheumatoid arthritis: a clinical and imaging study of abatacept (the ADJUST trial). Ann Rheum Dis 2010;69:510-16.

26. Bennett AN, Rehman A, Hensor EM, et al. The fatty Romanus lesion: a noninflammatory spinal MRI lesion specific for axial spondyloarthropathy. Ann Rheum Dis 2010;69:891-4.

27. Nam JL, Winthrop KL, van Vollenhoven RF, et al. Current evidence for the management of rheumatoid arthritis with biological disease-modifying antirheumatic drugs: a systematic literature review informing the EULAR recommendations for the management of RA. Ann Rheum Dis 2010;69:976-86.

28. Smolen JS, Landewé R, Breedveld FC, et al. EULAR recommendations for the management of rheumatoid arthritis with synthetic and biological disease-modifying antirheumatic drugs. Ann Rheum Dis 2010;69:964-75.

29. Tan RJ, Gibbons LJ, Potter C, et al.; BRAGGSS. Investigation of rheumatoid arthritis susceptibility genes identifies association of AFF3 and CD226 variants with response to anti-tumour necrosis factor treatment. Ann Rheum Dis 2010;69:1029-35.

30. Robinson JI, Barrett JH, Taylor JC, et al.; YEAR Consortium; BRAGGSS. Dissection of the FCGR3A association with RA: increased association in men and with autoantibody positive disease. Ann Rheum Dis 2010;69:1054-7.

31. Cohen SB, Keystone E, Genovese MC, et al. Continued inhibition of structural damage over 2 years in patients with rheumatoid arthritis treated with rituximab in combination with methotrexate. Ann Rheum Dis 2010;69:1158-61.

32. Haugeberg G, Bennett AN, McGonagle D, et al. Bone loss in very early inflammatory back pain in undifferentiated spondyloarthropathy: a 1-year observational study. Ann Rheum Dis 2010;69:1364-6.

33. Schoels M, Aletaha D, Smolen JS, et al. Follow-up standards and treatment targets in rheumatoid arthritis: results of a questionnaire at the EULAR 2008. Ann Rheum Dis 2010;69:575-8

34. Eyre S, Flynn E, Martin P, et al. No evidence for association of the KLF12 gene with rheumatoid arthritis in a large UK cohort. Ann Rheum Dis 2010;69:1407-8.

35. Eyre S, Hinks A, Flynn E, et al. Confirmation of association of the REL locus with rheumatoid arthritis susceptibility in the UK population. Ann Rheum Dis 2010;69:1572-3

36. Orozco G, Eyre S, Hinks A, et al.; Wellcome Trust Case Control consortium YEAR Consortium. Association of CD40 with rheumatoid arthritis confirmed in a large UK case-control study. Ann Rheum Dis 2010;69:813-16.

37. Emery $\mathbf{P}$, Durez P, Dougados $M$, et al. Impact of T-cell costimulation modulation in patients with undifferentiated inflammatory arthritis or very early rheumatoid arthritis: a clinical and imaging study of abatacept (the ADJUST trial). Ann Rheum Dis 2010;69:510-16

38. Saleem B, Keen $\mathrm{H}$, Goeb V, et al. Patients with RA in remission on TNF blockers: when and in whom can TNF blocker therapy be stopped? Ann Rheum Dis 2010;69:1636-42.

39. Barkham N, Coates LC, Keen H, et al. Double-blind placebo-controlled trial of etanercept in the prevention of work disability in ankylosing spondylitis. Ann Rheum Dis 2010;69:1926-8.

40. Emery P, Deodhar A, Rigby WF, et al. Efficacy and safety of different doses and retreatment of rituximab: a randomised, placebo-controlled trial in patients who are biological naive with active rheumatoid arthritis and an inadequate response to methotrexate (Study Evaluating Rituximab's Efficacy in MTX iNadequate rEsponders (SERENE)). Ann Rheum Dis 2010;69:1629-35.

41. Dixon WG, Hyrich KL, Watson KD, et al.; BSRBR Control Centre Consortium; British Society for Rheumatology Biologics Register. Influence of anti-TNF therapy on mortality in patients with rheumatoid arthritis-associated interstitial lung disease: results from the British Society for Rheumatology Biologics Register. Ann Rheum Dis 2010;69:1086-91. 